\title{
Plant-Influenced Gene Expression in the Rice Endophyte Burkholderia kururiensis M130
}

\author{
Bruna G. Coutinho, ${ }^{1,2}$ Danilo Licastro, ${ }^{3}$ Lucia Mendonça-Previato, ${ }^{4}$ Miguel Cámara, ${ }^{5}$ and Vittorio Venturi ${ }^{1}$ \\ ${ }^{1}$ Bacteriology Group, International Centre for Genetic Engineering \& Biotechnology, Padriciano 99, 34149 Trieste, Italy; ${ }^{2}$ The \\ Capes Foundation, Ministry of Education of Brazil, Cx postal 250, Brasilia, DF 70.040-020, Brazil; ${ }^{3}$ CBM S.c.r.l., Area Science \\ Park-Basovizza, Trieste, Italy; ${ }^{4}$ Universidade Federal do Rio de Janeiro, Centro de Ciências da Saúde, Instituto de Biofísica \\ Carlos Chagas Filho-Ilha da Cidade Universitária, CEP 21.990-400 Rio de Janeiro, RJ, Brazil; ${ }^{5}$ School of Life Sciences, \\ Centre for Biomolecular Sciences, University of Nottingham, Nottingham NG7 2RD, U.K.
}

Submitted 30 July 2014. Accepted 25 September 2014.

\begin{abstract}
Burkholderia kururiensis M130 is one of the few rice endophytic diazotrophic bacteria identified thus far which is able to enhance growth of rice. To date, very little is known of how strain M130 and other endophytes enter and colonize plants. Here, we identified genes of strain M130 that are differentially regulated in the presence of rice plant extract. A genetic screening of a promoter probe transposon mutant genome bank and RNAseq analysis were performed. The screening of 10,100 insertions of the genomic transposon reporter library resulted in the isolation of 61 insertions displaying differential expression in response to rice macerate. The RNAseq results validated this screen and indicated that this endophytic bacterium undergoes major changes in the presence of plant extract regulating $27.7 \%$ of its open reading frames. A large number of differentially expressed genes encode membrane transporters and secretion systems, indicating that the exchange of molecules is an important aspect of bacterial endophytic growth. Genes related to motility, chemotaxis, and adhesion were also overrepresented, further suggesting plant-bacteria interaction. This work highlights the potential close signaling taking place between plants and bacteria and helps us to begin to understand the adaptation of an endophyte in planta.
\end{abstract}

Rice (Oryza sativa) is the most important cereal feeding a large proportion of the world population (Ladha et al. 1997). However, its production is not increasing at a rate that is adequate to satisfy the demands of the growing population. It is estimated that, by 2020 , it will be necessary to double the amount of nitrogen $(\mathrm{N})$ fertilizer currently being used to achieve these higher yields (Ladha et al. 1997). An attractive alternative to chemical fertilizers in agriculture is the use of biofertilizers, consisting of bacteria which can provide $\mathrm{N}$ to the plant via biological atmospheric $\mathrm{N}_{2}$ fixation (Ladha and Reddy 1995; Reinhold-Hurek and Hurek 1998).

The use of bioinoculants is currently growing at over $10 \%$ yearly in order to decrease the use of chemical additives in agriculture. Beneficial endophytes residing inside plants are attractive candidates for the development of bioinoculants because

Corresponding author: V. Venturi; E-mail; venturi@icgeb.org

* The $\boldsymbol{e}$-Xtra logo stands for "electronic extra" and indicates that five supplementary figures and four supplementary tables are published online.

(C) 2015 The American Phytopathological Society they increase plant growth and resistance to pathogens (Compant et al. 2010; Hardoim et al. 2008; Reinhold-Hurek and Hurek 2011). It is believed that bacteria colonizing the plant interior might interact more closely with the host when compared with rhizospheric bacteria having less competition for nutrients and living in a more protected environment (Reinhold-Hurek and Hurek 1998). In addition to providing essential nutrients to plants, endophytes are also known to directly promote plant growth by the production or regulation of phytohormones (Hardoim et al. 2008; Reinhold-Hurek and Hurek 2011).

The most predominant and studied endophytes belong to the three major phyla Actinobacteria, Proteobacteria, and Firmicutes and, in addition to their in planta habitat, they are also normally found in the soil or rhizosphere, which represents the main source of endophytic colonizers. These soil- or rhizosphere-inhabiting endophytes are thought to reach the inside of plants through the phyllosphere or through seed (Compant et al. 2010). Endophytes can colonize different compartments of the plant apoplast, including the intercellular spaces of the cell walls and xylem vessels, and some of them are even able to colonize plant reproductive organs, such as seed, which allows them to be vertically transmitted from one generation to the other (Compant et al. 2010). However, we currently have little knowledge of how bacteria adapt, colonize, and live as endophytes in plants. Endophytes need to initially enter the plant endosphere, quickly adapt to the new environment, and overcome plant defense responses (Compant et al. 2010; Hardoim et al. 2008; Reinhold-Hurek and Hurek 2011). Endophytic colonization is believed to depend, in part, on motility, root penetration, and adaptation to the plant intercellular environment.

Endophytic Burkholderia kururiensis M130 was isolated from rice roots in Brazil and it was shown to promote plant growth, at least in part due to the increase in nitrogen availability (Baldani et al. 1997a and b, 2000). Inoculation experiments of rice with strain M130 have shown that up to $30 \%$ of the total nitrogen accumulated by the plant had been fixed by the bacteria, increasing rice growth and yield (Baldani et al. 1997a, 2000), which makes it a potential candidate for use as a biofertilizer or bioinoculant. Recently, we have sequenced the genome of $\mathrm{B}$. $\mathrm{ku}$ ruriensis M130 and observed that it possesses several genes potentially related to plant growth promotion, including the $a c c D$ gene encoding 1-aminocyclopropane-1-carboxylate deaminase and the nif gene cluster (Coutinho et al. 2013b). However, as is currently the case for most identified endophytes, no information is available on the molecular mechanisms that play an important role in plant colonization by these bacteria. 
Shidore and coworkers (2012) recently used a wholegenome microarray to investigate the response of the endophyte Azoarcus sp. strain BH72 to rice root exudate. These experiments revealed that $4.4 \%$ of the total protein-coding genes of the strain were differentially regulated in the presence of the exudate, including genes for pilin, signal transduction, and type IV secretion (Shidore et al. 2012). This work suggests that plant exudates may be an important switch for the endophytic lifestyle of these bacteria. Although this and a few other studies were able to identify genes differentially regulated in the rhizosphere or in the presence of plant root exudates (dos Santos et al. 2010; Mark et al. 2005; Rediers et al. 2003; Shidore et al. 2012), our knowledge of bacterial gene regulation occurring inside the plant is very limited. Cordeiro and coworkers (2013) performed proteomics experiments with endophytic Herbaspirillum seropedicae cultivated in the presence or absence of sugar cane extract (total plant macerate) and revealed a few proteins that might be differentially expressed inside the plant. These proteins were mainly related to metabolic changes and adaptations, which are probably involved in the establishment of the endophytic lifestyle. However, a general mode of regulation and target genes common to bacterial endophytes has not yet been identified.

In the present study, we analyzed the changes in gene expression of B. kururiensis M130 occurring during its interaction with the rice plant extract in order to have a btter understanding of the mechanisms involved in endophytism in this model. This was achieved via a more traditional screening of a transposon promoter-probe mutant genome bank and by a genomewide-scale RNAseq approach.

\section{RESULTS}

\section{B. kururiensis M130 shows differential expression of chromosomal transcriptional gene fusions in response to rice plant extract.}

In order to determine the differentially expressed genes of $B$. kururiensis M130 in the presence of rice plant extract, we constructed a promoter-probe genomic mutant bank of this strain using mTn5-GNm. This mTn5-based transposon possesses a kanamycin $(\mathrm{Km})$ resistance gene and a promoterless gusA reporter gene. The latter permits monitoring of gene expression when the transposon is inserted in the correct transcriptional orientation of an open reading frame (ORF) (Reeve et al. 1999).

In total, 10,100 independent mutants from the saturated $B$. kururiensis M130 genomic mutant bank, constructed as described below, were screened by patching them independently in duplicate in solid medium (containing X-GlcU) with or without macerated rice plant (Supplementary Fig. S1). Potential differentially regulated transposon insertions were selected on media plates by identifying colonies that displayed different levels of $\beta$-glucuronidase activity as observed by the naked eye in a medium-dependent color display. Independent colonies, each representing a single transposon insertion fusion, were scored based on a white-blue scale indicating upregulated or downregulated loci in the presence of rice plant extract by the variation in the color intensity (data not shown). This screen identified 61 transposon insertions showing differential regulation, of which 36 were upregulated and 25 were downregulated in the presence of rice plant extract (Table 1).

In order to validate these observations, the 61 transposon insertion fusions identified by the screening on solid medium were then subjected to $\beta$-glucuronidase activity quantification after growth in shaking-liquid media either in the presence or absence of macerated rice plant. Strain M130 presented similar growth rates in both conditions (Supplementary Fig. S2).
In this experiment, 58 fusions showed differential expression in the presence of rice plant extract, with 36 being upregulated and 22 downregulated. The fold changes of enzyme activity varied from 1.34 to 20.91 (Table 1; Supplementary Table S2). Almost all the insertions displayed an expression pattern similar to what was observed in solid media; interestingly, however, in the liquid enzyme assay, three of the transposon insertions presented a different type of regulation. More precisely, in the presence of rice plant extract, insertions 2 and 34 were downregulated in solid medium and upregulated in the liquid medium. In contrast, genomic insertion 160 displayed the opposite trend in solid and liquid conditions (Table 1). Moreover, three of the transposon insertions isolated on the solid media screen (i.e., mutants 19, 67, and 249) did not show differential regulation in the liquid enzyme assay (Table 1). These results suggest that the growth conditions (i.e., solid or liquid) might be important for regulation of these loci. With the intent to verify whether the differential response shown in the presence of macerated rice plant is dose dependent, we quantified the $\beta$-glucuronidase activity of eight transposon fusions in different concentrations of rice extract and, interestingly, we observed that, for most of them, the differential regulation increased together with the concentration of plant extract (Supplementary Fig. S3). However, in the presence of $10 \%$ macerated rice material, in most cases, the differential regulation of expression of the loci was abolished; this is most probably due to the toxicity of the plant macerate because, at this concentration, it had an effect also on the growth of the bacteria (data not shown).

In order to identify the genes in the differentially expressed transposon insertion mutants selected above, the location of the transposon was mapped using an arbitrary polymerase chain reaction (PCR) method (O'Toole and Kolter 1998a). Using this procedure, we were able to map 49 of the 61 mutants (Table 1). In order to map the other 12 transposon insertion fusions, we also performed genomic digestions and subcloning, aiming to isolate the genomic region flanking the $\mathrm{Km}$ resistance gene of the inserted transposon. However, this approach was also not successful for these 12 insertions; the reason for this is currently unknown. It is possible that the DNA regions associated with the location of the transposon contain genes that have deleterious effects when overexpressed in Escherichia coli.

The results obtained from the 49 mapped transposon insertions revealed that most of the genes that were differentially expressed in the presence of rice macerate were related to cellular processes and metabolism, including genes involved in the degradation of aromatic compounds, which are known to be abundant in the plant (e.g., p-hydroxybenzoate and protocatechuate) (Fig. 1). The second most abundant group were genes involved in transport of molecules across membranes, which are believed to be important for the exchange of nutrients within the plant (Fig. 1). Interestingly, in seven transposon insertion mutants, the gusA gene mapped in the opposite orientation with respect to transcriptional direction of an annotated gene of the B. kururiensis M130 genome (Tables 1 and 2; Fig. 1 ). The presence of antisense transcripts could be related to the existence of unidentified reading frames in the opposite strand of currently annotated genes; however, none of the potential ORF identified encode peptides displaying similarity to any other known protein, which could indicate the presence of a noncoding RNA (ncRNA) in these regions (Table 1). Two of these transposon insertions map at different locations on the opposite orientation of the same annotated ORF (i.e., transposon insertions 227 and 275), encoding a putative transmembrane protein (Table 2).

Several other transposon insertions also mapped on the same locus (Table 1), as is the case for four different insertions in 
the gene encoding a 5-dehydro-4-deoxyglucarate dehydratase (i.e., insertions $31,65,146$, and 267, with insertions 31 and 146 being siblings) (Table 1). This gene is most likely involved in the degradation of D-galacturonate, which is one of the major sugars present in plant cell walls. Interestingly, all of the genes identified that were likely to be involved in iron uptake were downregulated in the presence of rice plant extract. A transposon (insertion 144) was also found in a gene coding for a response regulator receiver protein; this gene possibly could be involved in transcriptional regulation in the presence of plant macerate (Table 1). The gene encoding this protein seems to be part of an operon together with a transcriptional regulator of the Crp/Fnr family (Fig. 2). In summary, this genetic screen revealed that, in the presence of rice macerate, B. kururiensis M130 differentially regulates several metabolism-related genes and membrane transporter genes that are likely to allow this endophyte to cope with the new environmental conditions.

\section{In planta studies}

of the promoter probe transposon insertions.

It was of interest to perform in planta studies with some of the transposon insertion mutants in order to evaluate the role of these genes in endophytic colonization and their expression in the plant environment. In order to carry out these experiments in rice plants, the mutants 146 and 193, which had transposon insertions in loci that were highly upregulated in the previous screen, were used (Table 1). Results showed that the mutants were able to endophytically colonize the roots of rice plants at the same level as the wild-type (WT) strain (Fig. $3 \mathrm{~A})$. The roots of plants inoculated with mutant 146 showed strong blue coloration when stained for $\beta$-glucuronidase activity, with the lateral roots displaying a more intense coloration (Fig. 3B). This qualitative result confirms high expression of the gene encoding a 5-dehydro-4-deoxyglucarate dehydratase in planta. However, roots of plants inoculated with mutant 193 did not show blue coloration upon staining (data not shown), which indicates that either the gene encoding the starvationsensing protein RspA is not expressed in planta or, more likely, the expression is too low to be detected by this staining methodology. In conclusion, neither of these two loci played a crucial role for endophyte colonization; however, one of them displayed high expression on the surface of roots pointing to a role for this gene in planta.

\section{B. kururiensis M130 transcriptome in response to rice plant extract.}

In order to perform a comparative analysis of B. kururiensis M130 response to rice macerate extract by different methods, to validate the screen of the transposon promoter probe library, and to obtain overall transcriptional profiling of this rice endophyte in plants, we performed strand-specific RNAseq analysis. Total RNA was purified from B. kururiensis grown in rich liquid media in the presence and absence of macerated rice extract, as described below.

Table 1. Burkholderia kururiensis M130 mTn5-GusNm insertions that show differential expression of $\beta$-glucuronidase in the presence of rice plant extract

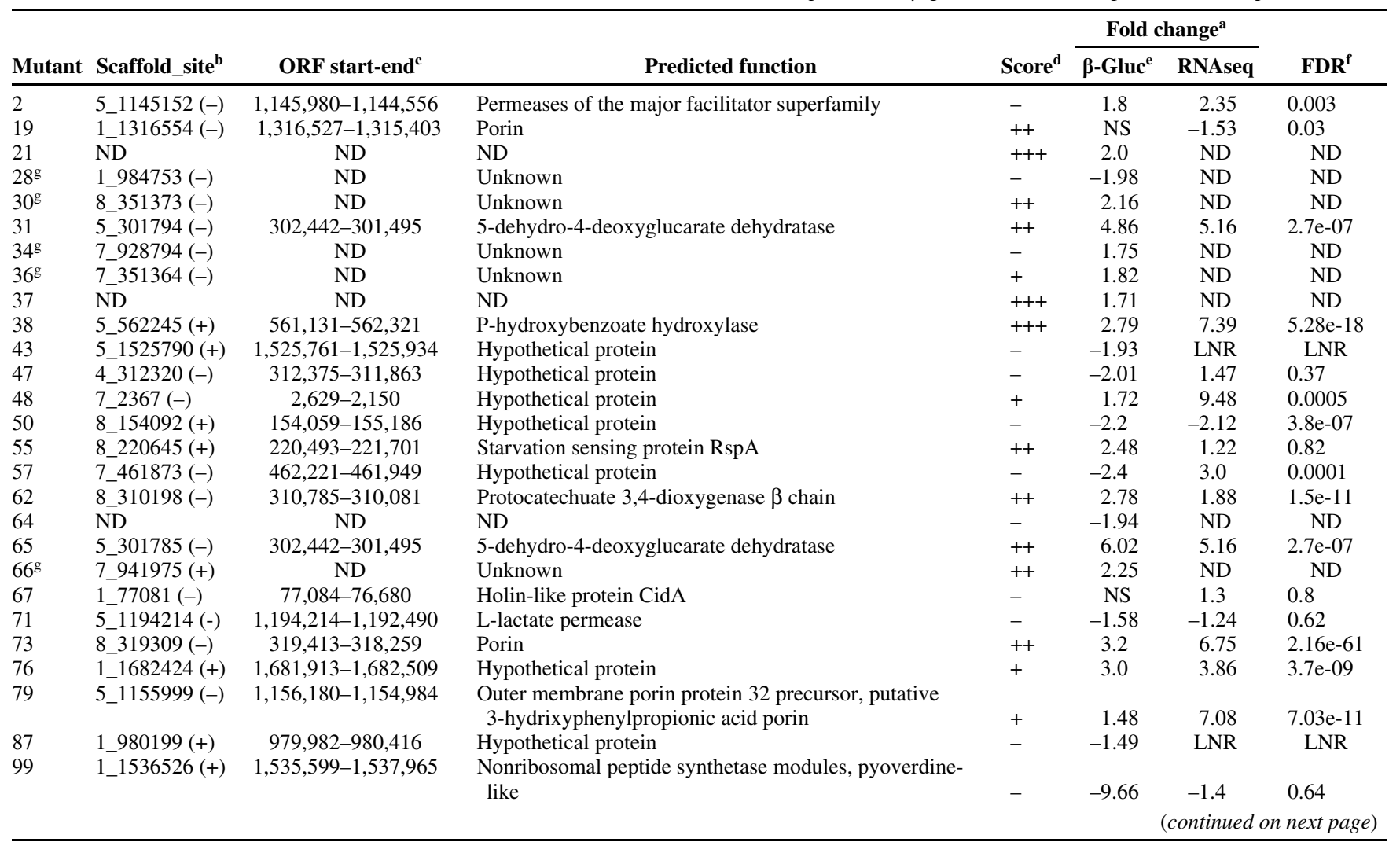

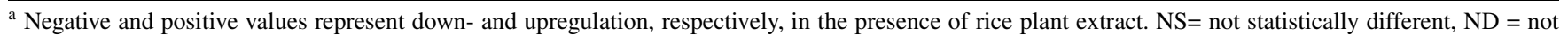
determined, and LNR $=$ low number of reads.

${ }^{\mathrm{b}}$ Scaffold_site of transposon insertion: + or - indicates the DNA strand of the B. kururiensis M130 genome in which the coding strand of the gusA gene of the transposon insertion was inserted.

${ }^{c}$ Open reading frame.

d Plate experiment score.

${ }^{\mathrm{e}}$ Fold change for $\beta$-glucuronidase activity.

${ }^{\mathrm{f}}$ False discovery rate (FDR) value for RNAseq.

${ }^{\mathrm{g}}$ Mutants that have the transposon inserted opposite to the transcriptional orientation of the annotated gene (antisense transcripts).
} 
Comparison of the RNAseq data with the transposon-insertion promoter-probe assay. The major reason for performing the RNAseq experiment was to validate the data obtained via the genetic screen of the transposon promoter-probe insertions in response to rice macerate. Therefore, we carefully compared the RNAseq data with the 49 mapped transposon insertions, keeping in mind that the growth media used in the two experimental set-ups was identical. However, there are two differences among the two experiments to consider: i) the genetic screen was performed using colonies in solid media, whereas the RNAseq data resulted from bacterial RNA purified from bacteria grown in shaking-liquid media; in order to make the comparison closer, the results generated with the RNAseq were compared with the ones derived from the $\beta$-glucuronidase enzyme quantification of the transposon insertions obtained when bacteria were also grown in liquid-shaking cultures; and ii) the screening using the transposon genomic library meant that each CFU was a knock-out mutant in a specific locus, which could have a direct or indirect effect on its own expression. This data comparison revealed that 27 of the 49 loci that were differentially expressed in the genetic screen also showed a similar trend of differential gene expression profiles in the RNAseq experiment with an false discovery rate (FDR) value $\leq 0.01$ (Table 1 ). These loci are mostly related to metabolism (especially of aromatic compounds) and different types of membrane transport systems. However, loci 57, 144, 178, 201, and 250 identified in the transposon screen presented a different type of regulation in the RNAseq experiment. The $\beta$-glucuroni- dase activity assays of these five transposon insertions showed a downregulation of these genes in the presence of rice plant extract whereas, in the RNAseq data, they were being upregulated (Table 1). To further analyze the expression of these five loci, we performed semiquantitative reverse-transcription polymerase chain reaction (SQ RT-PCR) and observed that, for two of them (i.e., transposon fusions 144 and 178), the patterns of expression correlated with the RNAseq results (Supplementary Table S3). We did not see difference in expression for the other three genes with this method and this is probably due to the low sensitivity of the SQ RT-PCR and the lower fold-change observed for these loci (Table 1). These results might suggest that the products of these genes may be involved in their own regulation, because the mutation caused by the transposon insertion might affect their pattern of expression. To further validate the RNAseq data, we selected four other genes to analyze by SQ RT-PCR and the results were comparable with the ones observed in the RNAseq.

The three transposon insertion loci which displayed differential expression only on plate solid medium and not in $\beta$-glucuronidase liquid assays (i.e., mutants 19, 67, and 249) were also not differentially expressed in the RNAseq experiment, which is in accordance because the RNAseq was also performed in shaking-liquid media (Table 1). Therefore, the expression of these three loci is possibly influenced by static growth in solid media and not liquid-shaking growth.

The regions of the seven transposon insertions identified as antisense transcripts were also analyzed on the RNAseq data

Table 1. (continued from preceding page)

\begin{tabular}{|c|c|c|c|c|c|c|c|}
\hline \multirow[b]{2}{*}{ Mutant } & \multirow[b]{2}{*}{ Scaffold_site ${ }^{b}$} & \multirow[b]{2}{*}{ ORF start-end ${ }^{c}$} & \multirow[b]{2}{*}{ Predicted function } & \multirow[b]{2}{*}{ Score $^{\mathrm{d}}$} & \multicolumn{2}{|c|}{ Fold change $^{\mathrm{a}}$} & \multirow[b]{2}{*}{ FDR $^{\mathbf{f}}$} \\
\hline & & & & & $\beta$-Gluc ${ }^{\mathrm{e}}$ & RNAseq & \\
\hline 103 & 1_1024300 (+) & $1,023,985-1,026,093$ & TonB-dependent receptor & - & -2.06 & -31.4 & $1.37 \mathrm{e}-95$ \\
\hline 121 & ND & ND & ND & +++ & 1.71 & ND & ND \\
\hline 123 & 4_65298 (-) & $66,227-65,079$ & Porin & ++ & 3.7 & 2.78 & $7.27 \mathrm{e}-09$ \\
\hline 124 & 1_1528111(+) & $1,516,822-1,533,051$ & $\begin{array}{l}\text { Nonribosomal peptide synthetase modules, pyoverdine- } \\
\text { like }\end{array}$ & - & -20.91 & 1.38 & 0.7 \\
\hline 130 & ND & ND & $\mathrm{ND}$ & +++ & 1.9 & ND & ND \\
\hline 131 & 5_1086991 (+) & $1,086,275-1,087,477$ & Acetyl-CoA acetyltransferase $\beta$-ketoadipyl CoA thiolase & - & -2.25 & -1.33 & 0.12 \\
\hline 135 & ND & ND & e & +++ & 2.03 & ND & ND \\
\hline 137 & 5_856719(+) & $856,003-856,830$ & 4-hydroxycinnamoyl CoA hydratase/lyase & + & 6.21 & 2.99 & $8.8 \mathrm{E}-07$ \\
\hline 144 & 5_1487519(-) & $1,487,503-1,487,195$ & Response regulator receiver protein & - & -4.04 & 9.82 & 0.0 \\
\hline 145 & 9_92313 (-) & $92,762-91,146$ & $\begin{array}{l}\text { RND efflux system, outer membrane lipoprotein, NodT } \\
\text { family }\end{array}$ & + & 1.92 & 1.42 & 0.123 \\
\hline 146 & 5_301785(-) & $302,442-301,495$ & 5-dehydro-4-deoxyglucarate dehydratase & ++ & 6.51 & 5.16 & 2.7E-07 \\
\hline 150 & $9 \_88340(-)$ & $88,688-87,810$ & $\begin{array}{l}\text { Membrane fusion component of tripartite multidrug } \\
\text { resistance system }\end{array}$ & - & -2.2 & -2.2 & $2.01 \mathrm{E}-07$ \\
\hline 160 & ND & ND & ND & ++ & -1.55 & ND & ND \\
\hline 163 & 1_1005739(+) & $1,005,244-1,005,789$ & $\begin{array}{l}\text { XdhC protein (assists in molybdopterin insertion into } \\
\text { xanthine dehydrogenase) }\end{array}$ & + & 2.5 & 9.76 & 0.00995 \\
\hline 164 & 5_303947(+) & $303,844-304,677$ & UDP-glucose 4-epimerase & ++ & 3.79 & 8.62 & $9.34 \mathrm{e}-07$ \\
\hline 178 & 7_512666(+) & $512,658-512,861$ & Hypothetical protein & - & -2.62 & 41.21 & $3.2 \mathrm{e}-12$ \\
\hline 187 & 1_715354 (+) & 714,919-715,893 & Threonine dehydratase, catabolic & - & -2.05 & -2.23 & $4.48 \mathrm{e}-08$ \\
\hline 193 & 8_220645(+) & $220,493-221,701$ & Starvation sensing protein RspA & +++ & 2.97 & 1.22 & 0.82 \\
\hline 194 & ND & ND & ND & +++ & 1.95 & ND & ND \\
\hline 201 & 5_652044(-) & $652,547-651,849$ & Phosphatase CheZ & - & -1.7 & 4.38 & $5.82 \mathrm{e}-13$ \\
\hline 219 & ND & ND & ND & +++ & 1.93 & ND & ND \\
\hline 226 & 1_1543336(+) & $1,541,329-1,543,323$ & $\begin{array}{l}\text { Ferric hydroxamate } \mathrm{ABC} \text { transporter, permease component } \\
\text { FhuB or 4'-phosphopantetheinyl transferase }\end{array}$ & t & -17.6 & -1.65 & 0.45 \\
\hline $227^{\mathrm{g}}$ & 5_90359 (+) & ND & Unknown & ++ & 1.82 & ND & ND \\
\hline 230 & 1_911723 (+) & $911,073-911,855$ & Sorbitol dehydrogenase & + & 2.0 & 4.6 & $1.59 \mathrm{e}-20$ \\
\hline 243 & $7 \_306591(+)$ & $306,335-309,208$ & Extracellular Matrix protein PelA & - & -2.12 & -1.03 & 0.86 \\
\hline 244 & 1_793114(-) & $793,611-792,112$ & Glycerol kinase & - & -2.02 & -2.42 & $7.48 \mathrm{e}-11$ \\
\hline 248 & ND & ND & ND & +++ & 1.34 & ND & ND \\
\hline 249 & 4_96716 (-) & $97,427-96,465$ & Agmatinase & - & NS & -1.43 & 0.45 \\
\hline 250 & 1_625434 (+) & $624,594-626,030$ & Ammonium transporter & - & -2.32 & 4.04 & $5.06 \mathrm{e}-13$ \\
\hline 251 & ND & ND & ND & +++ & 1.37 & ND & ND \\
\hline 262 & ND & ND & ND & +++ & 1.47 & ND & ND \\
\hline 267 & 5_301748 (-) & $302,442-301,495$ & 5-dehydro-4-deoxyglucarate dehydratase & ++ & 5.7 & 5.16 & $2.7 \mathrm{e}-07$ \\
\hline 270 & $1 \_1165866(+)$ & $1,164,892-1,166,553$ & 3-methylmercaptopropionyl-CoA ligase (DmdB) & + & 2.2 & 2.13 & $2.45 \mathrm{e}-07$ \\
\hline $275^{\mathrm{g}}$ & 5_90553 (+) & ND & Unknown & ++ & 1.76 & ND & ND \\
\hline
\end{tabular}


and the presence of complementary RNA reads was confirmed for all but two (i.e., insertions 36 and 66) (Supplementary Fig. S4). However in the absence of data corresponding to the size of the transcripts, no quantification could be performed. Interestingly, in the case of three antisense transcripts (i.e., insertions 28, 30, and 34), their sense-annotated ORF were also shown to be differentially regulated in the presence of rice plant macerate in the RNAseq results (Table 2).

We were not able to properly evaluate the expression of two loci of the transposon genetic screen because the number of RNA reads for these loci was below the quality threshold (i.e., for insertions 43 and 87) (Table 1).

Interestingly, the gene encoding the starvation-sensing protein RspA identified in transposon insertions 55 and 193, and which was upregulated in the presence of rice plant extract in the genetic screen, was not differentially expressed in the RNAseq experiment (Table 1). In the in planta studies described above, we did not detect expression using staining methodology of the root colonized by this strain carrying the transposon insertion. Thus, it is likely that the mutation on this gene affects its own expression.

Global analysis of the RNAseq transcriptome studies. Results of the RNAseq experiment showed that the expression of a large number of genes was significantly altered (FDR value $\leq$ 0.01 ) in response to rice macerate, with 1,825 genes being dif- ferentially expressed by twofold or more representing $27.7 \%$ of the protein-coding genes of B. kururiensis M130. Moreover, $69 \%$ of the differentially expressed genes were upregulated (Fig. 4) and 31\% were downregulated.

The highest percentage of differentially regulated genes corresponded to hypothetical proteins $(24.7 \%)$, the second most abundant group were genes involved in various cellular processes and metabolism (22\%), and the third were genes involved in secretion and transport (13.8\%) (Fig. 4). Interestingly, $7.8 \%$ of the differentially expressed genes were transcriptional regulators of several different regulatory families (Fig. 4), which results in a 1:12.8 ratio of genes coding for regulatory proteins to target genes. Moreover, $2.4 \%$ of the differentially regulated genes (predominantly upregulated) were found to code for proteins involved in degradation or biosynthesis of plant-related compounds; these include genes involved in the degradation of aromatic compounds such as vanillic and salicylic acids and genes involved in the production of molecules important for plant-growth promotion such as IAA and phenazines (Supplementary Table S4). Genes potentially involved in plant adhesion and colonization (e.g., type IV pili) as well as genes coding for efflux pumps were also found to be differentially regulated in the presence of plant macerate. Some of the pumps belong to resistance nodulation and cell division family (RND) efflux systems that might be involved in bacterial defense against

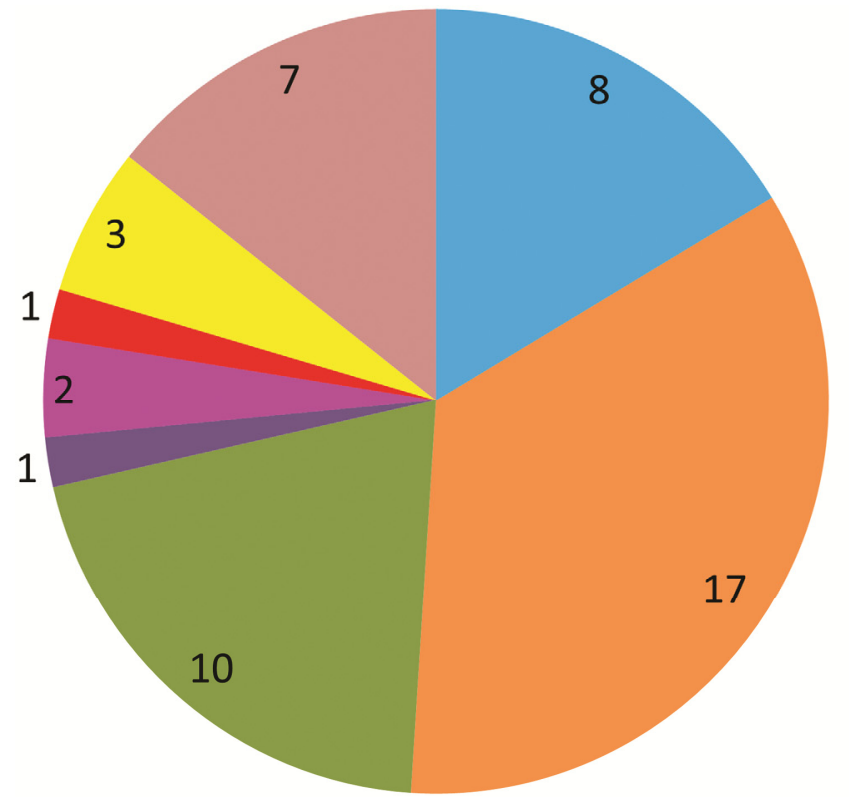

Hypothetical proteins

- Cellular processes/ Metabolism

Transport

Regulation

Biofilm

- Chemotaxis

Iron uptake

Antisense transcript

Fig. 1. Functional classification of the genes showing differential expression of $\beta$-glucuronidase in the presence of rice plant extract.

Table 2. Burkholderia kururiensis M130 mTn5-GusNm insertions that had the transposon inserted in the opposite orientation of the annotated gene

\begin{tabular}{|c|c|c|c|c|c|c|c|}
\hline \multirow[b]{2}{*}{ Mutant } & \multirow[b]{2}{*}{ Scaffold_site ${ }^{b}$} & \multicolumn{2}{|c|}{ Annotated ORF ${ }^{a}$} & \multirow[b]{2}{*}{ Transposon/ORF ${ }^{c}$} & \multirow[b]{2}{*}{ Predicted function of the annotated ORF } & \multicolumn{2}{|c|}{ RNAseq } \\
\hline & & Start & End & & & Fold change $^{d}$ & FDR $^{\mathrm{e}}$ \\
\hline 28 & 1_984753 & 984,226 & 984,864 & $-1+$ & Alkyl hydroperoxide reductase subunit $\mathrm{C}$-like protein & 1.34 & $4.1 \mathrm{e}-08$ \\
\hline 30 & 8_351373 & 350,600 & 351,676 & $-1+$ & Dipeptide transport system permease protein DppB & 2.89 & 0.00013 \\
\hline 34 & 7928794 & 928,620 & 928,934 & $-1+$ & Hypothetical protein & 2.83 & $1.9 \mathrm{e}-07$ \\
\hline 36 & 7_351364 & 351,147 & 352,178 & $-1+$ & 2-hydroxy-6-oxo-6-phenylhexa-2,4-dienoate hydrolase & -1.47 & 0.16 \\
\hline 66 & 7_941975 & 941,976 & 940,525 & $+/-$ & Catalase & 1.21 & 0.48 \\
\hline 227 & 5_90359 & 90,922 & 90,299 & $+1-$ & Probable transmembrane protein & 1.04 & 0.9 \\
\hline 275 & 5_90553 & 90,922 & 90,299 & $+/-$ & Probable transmembrane protein & 1.04 & 0.9 \\
\hline
\end{tabular}

${ }^{a}$ Annotated open reading frame (ORF).

${ }^{\mathrm{b}}$ Scaffold_site of transposon insertion.

${ }^{c}$ Strand transposon/annotated ORF.

${ }^{\mathrm{d}}$ Gene expression values expressed as fold change; negative and positive values represent down- and upregulation, respectively, in the presence of rice plant extract.

${ }^{\mathrm{e}}$ False discovery rate (FDR) value. 
toxic-plant metabolites. Other loci that might be involved in plant-bacteria interactions were related to chemotaxis, flagella, the type VI secretion system, and the BraI/R quorum-sensing system.

\section{DISCUSSION}

In this study, we have used a transposon-promoter-reportersystem and RNAseq to study gene expression of the endophyte B. kururiensis M130 when exposed to rice plant macerate. To interpret this data, one has to keep in mind that the transposon insertion might have an effect on the phenotype of the screen because it inactivates the gene (or possibly genes if there is an operonic organization) in which it inserts. This is not the case for the transcriptomic experiments using strand-specific RNAseq, in which the WT strain was used. The RNAseq experiment provided a global view of the gene expression profile and was validated by the genetic screen of the transposon promoter-probe library. Another remarkable difference of the two experimental set-ups is that, in one, the screen involves bacteria grown on solid-plate media, whereas the RNAseq experiment indicates gene expression when bacteria are grown in liquid-shaking cultures. Moreover, in addition to annotated genes, the combination of both techniques allowed us to also identify antisense transcripts potentially involved in plant-bacteria interactions.

Both experimental set-ups presented here used total autoclaved rice macerate as a source of plant molecules. Because B. kururiensis M130 is an endophyte which can live inside the rice plant in different locations and tissues, we believe that bacteria will be exposed to many different plant-produced molecules; hence, using complete plant macerate should provide a gene expression profile that includes all the important or major loci. It is likely, however, that some plant components to which $B$. kururiensis responds might have been inactivated or degraded by autoclaving the macerate. Preparation of the rice macerate performed here has been described previously and it allowed the identification of a novel subfamily of LuxR regulators that responds to plant compounds (Ferluga and Venturi 2009; Ferluga et al. 2007; Subramoni et al. 2011).

Results presented here indicate that the $B$. kururiensis endophyte undergoes major changes in its metabolism when exposed to plant macerate, probably as a result of the availability of a new range of nutrients and signals. This result is in agreement with observations from transcriptome and proteomic analysis of other bacteria growing in the presence of root exudates and

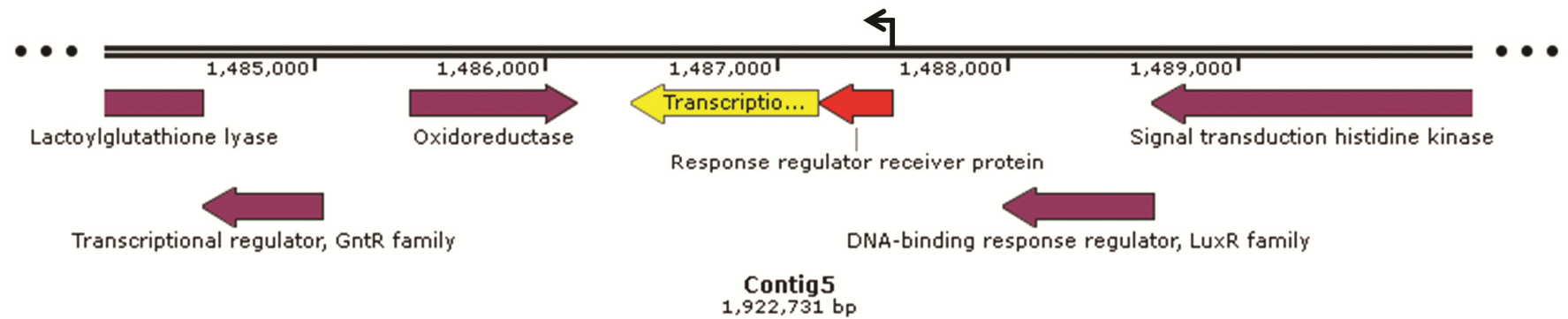

Fig. 2. Graphical representation of the region of transposon insertion 144 in Burkholderia kururiensis M130 mTn5-GNm. Genes were annotated using the RAST-Server. The black arrow represents the insertion site of the transposon and the orientation of its gusA gene. The gene in yellow is a transcriptional regulator of the Crp/Fnr family.
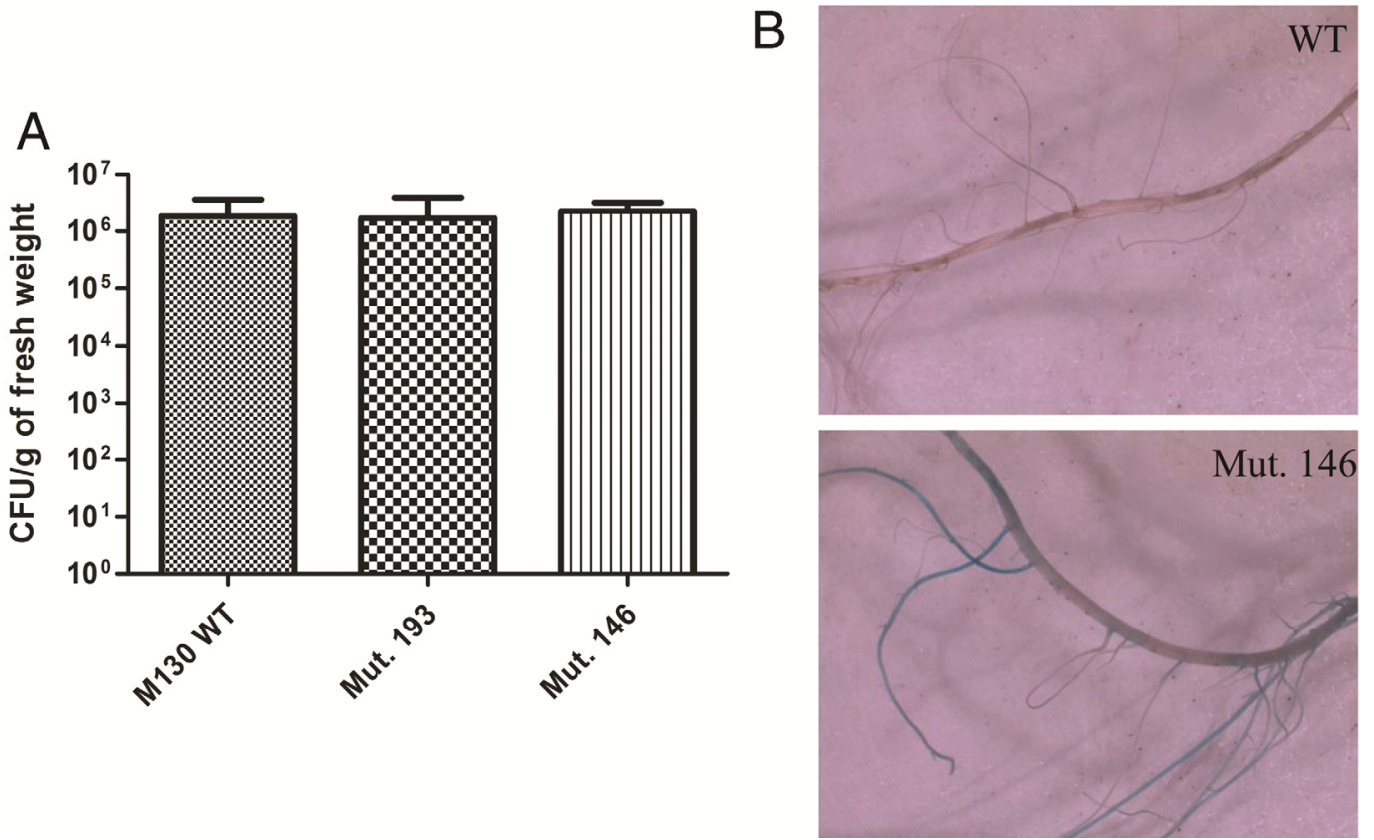

Fig. 3. Rice colonization assays performed with Burkholderia kururiensis M130 (wild type [WT]) or its mTn5-GusNm mutants 146 and 193 . A, Endophytic root colonization levels; bacterial endophytic colonization was measured by grinding and plating surface-sterilized roots after 14 days, and CFU/g levels of eight replicates from two independent experiments are plotted. Bars indicate means \pm standard deviations. B, $\beta$-Glucuronidase (GUS) staining of roots of rice plants 14 days after inoculation with WT strain or with mutant 146. Control plants inoculated with the WT strain showed no GUS activity. GUS activity on plants inoculated with mutant 146 was observed on all roots, with the most intense color development on the lateral roots. 
plant extracts. In these reports, a major change in the expression of genes related to different aspects of metabolism such as aromatic compound catabolism, energy generation, and amino acid biosynthesis and metabolism was observed (Cordeiro et al. 2013; Mark et al. 2005; Shidore et al. 2012). In addition, differential expression of several loci encoding for families of transporter proteins have also been observed, indicating that several molecules (e.g., aromatic compounds and toxic plant metabolites) are most probably transported inside or outside bacteria when they grow in planta.

Both experimental approaches identified that loci involved in the uptake of iron were downregulated in the presence of rice macerated extract. The medium used for these experiments (i.e., King's B [KB] medium) is poor in available iron when compared with other rich media (King et al. 1954); thus, these results indicate that the plant extract provides iron to $B$. kururiensis, decreasing the expression of genes involved in iron uptake.

The gene encoding for a response regulator receiver protein identified with the transposon-reporter system (i.e., transposon insertion 144) was shown to also be highly upregulated in the presence of plant macerate, according to the RNAseq experiment (Table 1). Interestingly, the RNAseq data revealed that the transcriptional regulator located downstream of this locus, which belongs to the $\mathrm{Crp} / \mathrm{Fnr}$ family (i.e., 8.6-fold-change) was also upregulated (Fig. 3). The Crp/Fnr family of regulators is often involved in the regulation of bacterial metabolic versatility, virulence factors, degradation of aromatic compounds, nitrogen fixation, photosynthesis, and various types of respiration and stress-related features. The regulators are able to respond to a broad spectrum of intracellular and exogenous signals such as cAMP, anoxia, oxidative stress, carbon monoxide, or temperature (Körner et al. 2003) and, in plant-related bacteria, this family of regulators is well known for its role in the regulation of the symbiotic nitrogen fixation process in rhizobia (Fischer 1994).

Interestingly, the type VI secretion system (T6SS) of $B . k u$ ruriensis M130 is downregulated in the presence of plant rice extract. The T6SS in bacteria has recently been identified and its mode of action is still being characterized; however, it is known that it can power secretion of proteins between cells by utilizing a contractile phage sheath-like structure (Basler et al. 2012; Leiman et al. 2009). Moreover, there is increasing evidence that the T6SS has important roles in the interaction with eukaryotic hosts as well as with other bacteria (Basler et al. 2013; Bingle et al. 2008; Cascales 2008; Filloux et al. 2008).

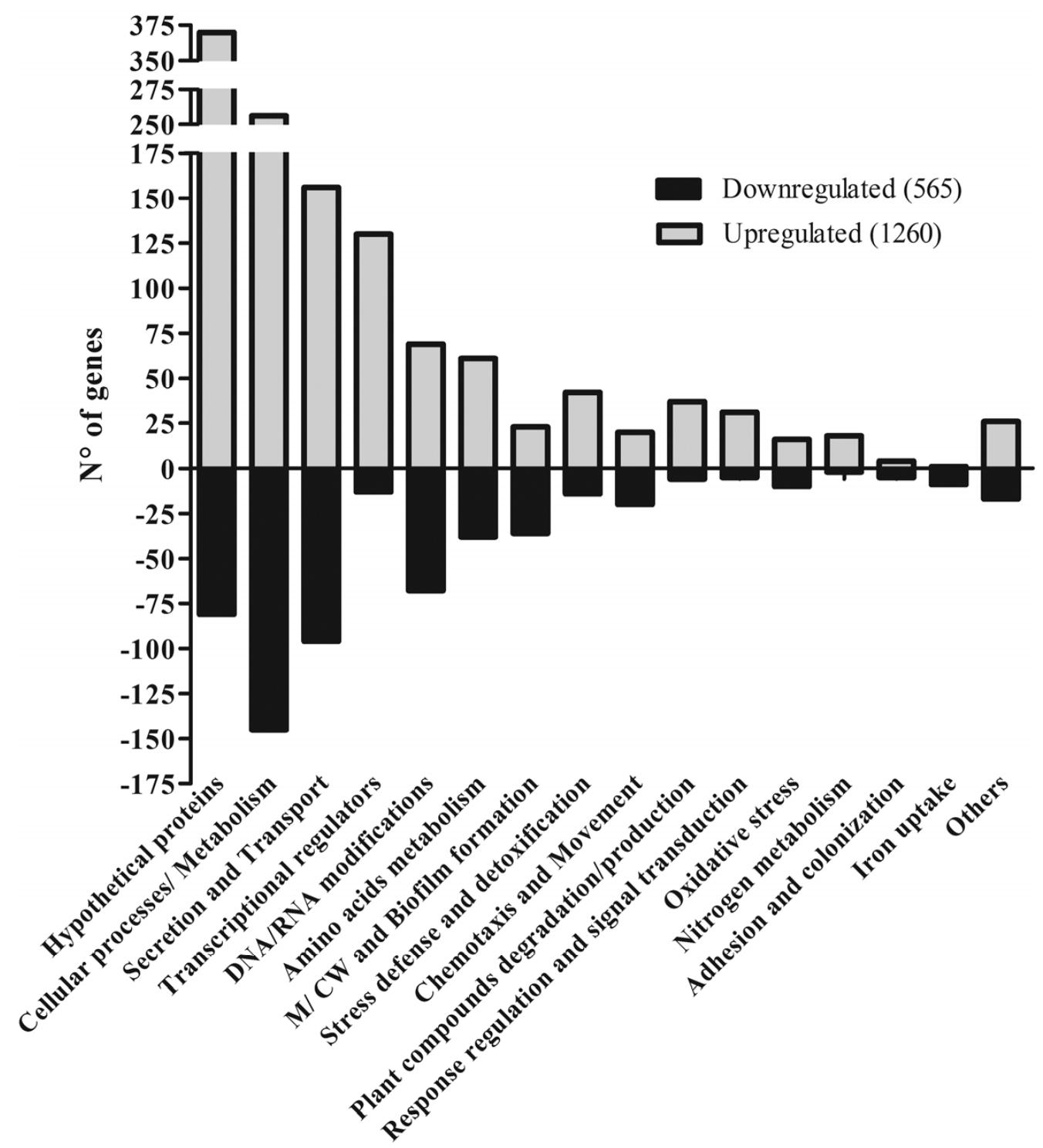

Fig. 4. Functional classification of differentially expressed genes in Burkholderia kururiensis M130 in response to rice plant extract by transcriptome analysis. Only genes with a fold difference greater than 2 are included. $\mathrm{M}=$ membrane and $\mathrm{CW}=$ cell wall. 
Mutations in the T6SS of the potato pathogen Pectobacterium atrosepticum led to increased virulence (Mattinen et al. 2008), whereas T6SS mutations in the endophyte Azoarcus sp. strain BH72 resulted in enhanced colonization of rice plants (Shidore et al. 2012). Similarly, inactivation of T6SS of Rhizobium leguminosarum enabled a strain that is normally not able to form functional nodules on pea to infect pea plants and fix nitrogen (Bladergroen et al. 2003). Therefore, it is possible that the T6SS elicits a host defense response and, thus, it will be important to repress its expression in a beneficial endophyte.

It was observed that genes involved in flagella biosynthesis are mostly being downregulated; however, genes involved in chemotaxis and in the flagellar motor rotation are upregulated in the presence of rice macerate. Chemotaxis is the mechanism through which bacteria are able to efficiently respond to changes in the chemical composition of the environment, moving toward favorable environments and avoiding unfavorable ones by controlling the flagellar movement. However, flagellins are known to elicit defense responses in plants because they are recognized as pathogen-associated molecular patterns (PAMPs) (Felix et al. 1999). Hence, the downregulation of genes involved in flagellin synthesis would allow B. kururiensis to escape host defense responses. This has been observed in transcriptome experiments with Pseudomonas aeruginosa PAO1 and Azoarcus sp. strain BH72 in response to root exudates (Mark et al. 2005; Shidore et al. 2012). Taken together, the downregulation of flagella biosynthesis and the upregulation of functions related to flagellar motor rotation and chemotaxis might indicate that, at the same time, bacteria is induced to hide its flagellin PAMPs and move faster in the plant environment. Swimming experiments further confirmed these results and showed that the macerated rice plant induces motility (results of these experiments were $5.52 \pm 0.1 \mathrm{~cm}$ swimming zone in $\mathrm{KB}$ medium and $6.68 \pm 0.2 \mathrm{~cm}$ in $\mathrm{KB}$ medium with $5 \%$ macerated rice plant) (Supplementary Fig. S5).

Similarly, genes probably involved in root surface colonization (e.g., encoding type IV pili) are also differentially regulated in the presence of rice macerate, as well as genes encoding components of efflux systems. The differential regulation of type IV pili-encoding genes also has been reported in plantassociated bacteria grown in the presence of root exudates (Mark et al. 2005; Shidore et al. 2012). This type of pili was reported to be important for endophytic rice colonization, root attachment, twitching motility, and biofilm formation (Bohm et al. 2007; Dörr et al. 1998; O'Toole and Kolter 1998b; Shidore et al. 2012). Efflux pumps are transport proteins involved in the extrusion of toxic substrates into the external environment.
Several of these pumps were shown to be differentially regulated in the presence of rice macerate, such as components of the RND efflux system, which has been reported to play an active role in the successful colonization of the apple tree by the phytopathogen Erwinia amylovora (Burse et al. 2004). The study of Burse and coworkers (2004) suggests that the AcrAB system of E. amylovora is induced in planta and is involved in the resistance toward phytoalexins (plant secondary metabolites with antimicrobial activity). Our results obtained with the RNAseq experiments suggest that, for endophytes, this type of efflux system might be important in their survival against plant defenses, because they are highly upregulated in the presence of plant macerate with fold changes as high as 97.

$\mathrm{N}$-acyl homoserine lactone (AHL) quorum-sensing (QS) via the BraI/R system has been shown to play a role in endophytic colonization and plant-growth promotion in B. kururiensis M130 (Suárez-Moreno et al. 2010). The BraI/R QS system was found to be upregulated in the presence of rice plant macerate in the RNAseq experiment. Transcriptome studies have been performed to identify the BraI/R regulon in other closely related species of plant-beneficial Burkholderia spp., highlighting the fact that it is species-specific and no core regulon is present (Coutinho et al. 2013a). Currently, the $\mathrm{BraI} / \mathrm{R}$ regulon of $B$. kururiensis $\mathrm{M} 130$ is unknown and it is likely that it regulates loci that play important roles in endophytism. In addition, the BraI/R regulator called RsaL (SuárezMoreno et al. 2008) was not shown to be differentially expressed in response to rice macerate, which indicates that a currently unidentified regulator is most probably involved in the regulation of this QS system in response to plant macerate.

Cordeiro and coworkers (2013) used total plant extract and proteomics in order to identify genes important for the endophytic lifestyle of the $H$. seropedicae endophyte. They analyzed differences in the proteome in the presence or absence of sugar cane extract and were able to identify 16 differentially expressed proteins, most of them being metabolism related (Cordeiro et al. 2013). In B. kururiensis M130, we observed six orthologs of the 16 reported in the proteomics study with fold-changes higher than 2 and FDR values lower than 0.01 in response to rice macerate (Table 3). Most of these loci display differential expression, with a pattern similar to that seen for $H$. seropedicae. Interestingly, one of these is the FusA elongation factor G1, and B. kururiensis has two copies of this gene. One of the fusA genes is upregulated like the one of $H$. seropedicae while the other is downregulated. In addition, the RpsA $30 \mathrm{~S}$ ribosomal subunit $\mathrm{S} 1$ is upregulated in $H$. seropedicae and the corresponding gene is downregulated in B. kururiensis.

Table 3. Differentially expressed proteins and genes of the endophytes Herbaspirillum seropedicae SmR1 and Burkholderia kururiensis M130 grown in the presence of sugar cane or rice plant extract, respectively ${ }^{\mathrm{a}}$

\begin{tabular}{|c|c|c|c|c|c|c|c|c|c|c|}
\hline \multirow[b]{2}{*}{ ID $H S^{\mathbf{b}}$} & \multirow[b]{2}{*}{ Gene function } & \multirow[b]{2}{*}{ FC $H S^{\mathbf{c}}$} & \multirow[b]{2}{*}{ ID $B K^{d}$} & \multicolumn{3}{|c|}{ Gene location } & \multicolumn{2}{|c|}{ Blast } & \multicolumn{2}{|c|}{ RNAseq } \\
\hline & & & & Contig & Start & Stop & Score ${ }^{\mathrm{e}}$ & E-value $^{f}$ & FC & FDR \\
\hline Hsero_3276 & DapA dihydrodipicolinate synthase protein & 2.09 & fig|984307.6.peg.470 & 7 & 543,771 & 542,884 & 175 & $5.0 \mathrm{e}-45$ & 8.68 & $8.5 \mathrm{e}-13$ \\
\hline \multirow[t]{2}{*}{ Hsero_0111 } & FusA elongation factor $\mathrm{G} 1$ & 2.52 & fig|984307.6.peg.5368 & 7 & 838,255 & 840,360 & 1,144 & 0.0 & -3.18 & $9.4 \mathrm{e}-09$ \\
\hline & & & fig|984307.6.peg.756 & 8 & 18,080 & 20,182 & 1,118 & 0.0 & 2.3 & 0.0 \\
\hline \multirow[t]{2}{*}{ Hsero_0415 } & $\begin{array}{l}\text { Bifunctional } \\
\text { phosphoribosylaminoimidazolecarboxamide }\end{array}$ & & & & & & & & & \\
\hline & formyltransferase/IMP cyclohydrolase & Absent & fig|984307.6.peg.893 & 7 & 981,193 & 982,758 & 815 & 0.0 & -2.16 & $2.3 e-11$ \\
\hline Hsero_3923 & Glutamate synthase small subunit oxidoreductase & Absent & fig|984307.6.peg.5425 & 8 & 67,839 & 69,305 & 801 & 0.0 & -2.61 & $5.5 \mathrm{e}-16$ \\
\hline Hsero_3689 & RpsA 30s ribosomal protein $\mathrm{S} 1$ & 2.58 & fig $\mid 984307.6 . p e g .3690$ & 5 & 173,542 & 175,272 & 934 & 0.0 & -2.34 & $2.7 \mathrm{e}-08$ \\
\hline Hsero_0097 & TufB EF-Tu elongation factor protein & Absent & fig|984307.6.peg.5356 & 8 & 1,002 & 2,192 & 736 & 0.0 & -2.68 & $4.3 e-66$ \\
\hline
\end{tabular}

\footnotetext{
${ }^{\mathrm{a}} \mathrm{ID}=$ gene identification, $\mathrm{FC}=$ fold change, and FDR $=$ false discovery rate value.

${ }^{\mathrm{b}}$ Gene identify for $H$. seropedicae.

${ }^{\mathrm{c}}$ Fold change for $\mathrm{H}$. seropedicae according to Cordeiro and associates (2013). "Absent" indicates protein absent in the presence of sugar cane extract.

${ }^{\mathrm{d}}$ Gene identity for B. kururiensis according to annotation performed by the RAST-Server (Aziz et al. 2008).

${ }^{\mathrm{e}}$ Score (bits).

${ }^{\mathrm{f}}$ Expect value.
} 
The 30S ribosomal protein S1 (RpsA) is the largest ribosomal protein in the 30S subunit of Escherichia coli ribosome; however, its association with the ribosome is weak and reversible (Subramanian 1983). Moreover, RpsA is the only ribosomal protein with documented affinity for mRNA (Draper et al. 1977) and is essential for growth, being required for translation of bulk mRNA in E. coli (Briani et al. 2008; Sorensen et al. 1998). For these reasons, RpsA has been considered a translation factor rather that a ribosomal protein. The reason for differential regulation of this protein upon exposure to plant macerate is currently unknown. Interestingly, RpsA expression has also been shown to be regulated in other plant-bacteria associations; for instance, in the sugar cane associated bacterium Gluconacetobacter diazotrophicus (dos Santos et al. 2010; Lery et al. 2008)

Elongation factor (EF)-Tu is one of the most abundant proteins in bacteria and it plays an essential role in the elongation phase of protein biosynthesis. However EF-Tu, just like flagellin, is also recognized by the plant as a PAMP, activating the plant innate immune response (Kunze et al. 2004). These results suggest that the downregulation of EF-Tu and flagellin by plant macerate is part of a coordinated regulation of proteins able to elicit plant defense mechanisms to enable temporal control of plant response and allow plant colonization by the endophyte.

In our genetic screen, we have identified potential antisense RNAs (asRNAs) that are differentially expressed in the presence of rice plant extract. A similar methodology or approach was used in the identification of asRNAs of Mycoplasma genitalium, proving to be a robust technique for this type of analysis (Lluch-Senar et al. 2007). The RNAseq experiments further confirmed the transcription of these asRNAs and revealed that, for some of them, the sense mRNA is also differentially expressed in the presence of plant macerate (Table 2). The presence of antisense transcripts has been linked to the regulation of gene expression in bacteria. asRNAs are encoded on the DNA strand opposite another gene and are able to form extensive base-pairing interactions with their corresponding sense RNA. This type of ncRNA has been shown to have roles on the repression of transposases and toxic protein synthesis, regulation of the levels of transcriptional regulators, and modulation of the levels of metabolic and virulence proteins (Thomason and Storz 2010). It is likely that the expression level of an asRNA is coupled to the expression level of its corresponding mRNA, and evidence is accumulating that some asRNA respond to environmental cues (Georg and Hess 2011). For instance, the transcription of $a s \_m c c A$, an asRNA from Clostridium acetobutylicum that controls a sulfur metabolic operon, is regulated in response to sulfur availability (Andre et al. 2008). It was not the scope of this work to focus on asRNAs; however, recent research has shown that they are widespread in bacteria, being found also in plant pathogens (Filiatrault et al. 2010; Georg and Hess 2011; Schmidtke et al. 2012); currently, to our knowledge, there are no studies on their role in plant-bacteria interactions.

The reasons for the lack of RNA reads in the direction of the gusA gene in transposon insertions 36 and 66 is unknown; however, from the $\beta$-glucuronidase quantification results, it is possible to observe that these loci have a low transcription rate. Moreover, the RNA isolation procedure used here does not efficiently purify low molecular weight RNAs (e.g., small RNAs); therefore, it is likely that we did not detect a complete representation of ncRNAs expressed under the conditions evaluated here.

In this study, we have identified genes potentially regulated during the endophytic establishment of B. kururiensis M130 in rice plants. It is likely that endophytic bacteria utilize different strategies to interact with their hosts; however, some of these features such as the differential regulation of molecules that elicit plant immune responses and those involved in root attachment are likely to be common. It is important to understand the mechanisms of regulation of these loci and the molecules or signals of the plant involved in inducing major changes in the bacterial behavior required for in planta adaptation. A careful analysis of the transcriptional regulators and of the potential ncRNAs being differentially expressed in the presence of plant macerate is an important step in addressing these questions.

\section{MATERIALS AND METHODS}

\section{Bacterial strains, plasmids, media, and recombinant DNA techniques.}

Rifampicin (Rif)-resistant B. kururiensis M130 WT (Baldani et al. 1997a) and its derivative strains were grown at $30^{\circ} \mathrm{C}$ in $\mathrm{KB}$ medium (King et al. 1954) or M9 minimal medium supplemented with glucose (Sambrook et al. 1989). Medium containing macerated rice material was prepared as follows: 20 to $25 \mathrm{~g}$ of rice plant was macerated in the presence of liquid nitrogen, added to $400 \mathrm{ml}$ of $\mathrm{KB}$ or M9 medium, autoclaved, and filtered to remove large plant materials. E. coli strains were grown in Luria-Bertani (LB) medium at $37^{\circ} \mathrm{C}$. The plasmid pGEM-T Easy Vector (Promega Corp., Madison, WI, U.S.A.) was used for cloning. Antibiotics were added when required at the following final concentrations: ampicillin (Amp) at $100 \mu \mathrm{g} \mathrm{m} l^{-1}, \mathrm{Km}$ at $50 \mu \mathrm{g} \mathrm{ml}^{-1}$ (E. coli) or $100 \mu \mathrm{g} \mathrm{ml} l^{-1}(B$. kururiensis), nitrofurantoin (Nf) at $100 \mu \mathrm{g} \mathrm{ml}^{-1}$, and Rif at $100 \mu \mathrm{g} \mathrm{ml}^{-1}$. The $\beta$-glucuronidase substrate $\mathrm{X}-\mathrm{GlcU}$ (Life Technologies, Carlsbad, CA, U.S.A.) was incorporated in solid medium at $40 \mu \mathrm{g} \mathrm{ml}^{-1}$.

All recombinant DNA techniques were performed as described previously (Sambrook et al. 1989). Plasmids were purified by using EuroGold columns (EuroClone, Italy); total DNA from Burkholderia spp. was isolated by sarkosyl-pronase lysis, as described previously (Better et al. 1983). Generated plasmids were sequenced-verified by Macrogen (Europe). The sequences of the primers used are given in Supplementary Table S1.

\section{Construction of the transposon promoter-probe genomic mutant bank in $B$. kururiensis and mapping of transposon insertion sites.}

Plasmid pCRS530 (Reeve et al. 1999) carrying the mTn5GNm (containing gusA- $\mathrm{P}_{t a c}-n p t I I-\mathrm{T}_{t r p A}$ ) was harbored in E. coli S17-1 (Simon et al. 1983) and biparental conjugation was performed in order to conjugate this plasmid into B. kururiensis M130. The transconjugants harboring the mTn5-GNm into the chromosome were selected on $\mathrm{KB}$ plates containing $\mathrm{Km}, \mathrm{Nf}$, and Rif and incubated for $18 \mathrm{~h}$ at $30^{\circ} \mathrm{C}$. Several conjugations were performed in order to obtain over 100,000 independent transposon insertions. The DNA sequence-flanking transposon mutants in B. kururiensis M130 were determined using an arbitrary PCR procedure, as previously described (O'Toole and Kolter 1998a). In this method, the DNA flanking the transposon insertion site was enriched in two rounds of amplification using primers specific to the ends of the mTn5-GNm element and primers of random sequence that annealed to chromosomal sequences flanking the transposon.

\section{Total RNA isolation.}

RNA isolations were carried out from three independent cultures of B. kururiensis M130 grown in KB medium and KB medium supplemented with rice plant macerate. The cultures were incubated at $30^{\circ} \mathrm{C}$ and $180 \mathrm{rpm}$ until they reached an optical density at $600 \mathrm{~nm}$ of 3.0; this stage was chosen because it is the 
beginning of the stationary phase. RNA isolation was carried out from $2 \times 10^{9}$ cells using the Ribopure bacteria RNA isolation kit (Ambion Inc., Austin, TX, U.S.A.), following the manufacturer's instructions. Isolated RNA was treated with DNase at $37^{\circ} \mathrm{C}$ for $1 \mathrm{~h}$ and purified. The purity of RNA was assessed by PCR on total RNA (250 ng) with GoTaq polymerase (Promega Corp.) using 16S_M130 primers. RNA quality and concentration were assessed by Nanodrop (Thermo Scientific, Wilmington, DE, U.S.A.) and agarose gel electrophoresis.

\section{RNAseq experiment and analysis.}

RNAseq experiments were performed by IGA Technology Services Srl (Udine, Italy). Briefly, RNA samples were first treated with the Ribo-Zero Magnetic Kit specific for gramnegative bacteria (Epicentre, Madison, WI, U.S.A.) in order to deplete ribosomal RNA (rRNA). Total RNA $(1.5 \mu \mathrm{g})$ was used as starting material following the standard protocol. The purification of rRNA-depleted samples was performed by using Agencourt RNAClean XP kit (Beckman Coulter, U.S.A.), as described in the manufacturer's protocol. rRNA-depleted RNA samples were then processed using Encore Complete Prokaryotic RNA-Seq Library Systems from Nugen (NuGEN Technologies, Inc., CA, U.S.A.). Pools of six samples were loaded on one lane of Illumina flowcell and clusters created by Illumina cBot. The clusters were sequenced on the Illumina HiSeq2000 (Illumina Inc.). One lane in six-plex was run, obtaining approximately 20 million single reads per sample; each read was 50 bp long. Raw reads were deposited in the Sequence Read Archive of the National Center for Biotechnology Information with the number SRP044730.

CLC-Bio Genomics Workbench software (CLC Bio, Denmark) was used to calculate gene expression levels based on the approach of Mortazavi and associates (2008) and foldchanges between samples. Gene functions were annotated using the RAST-Server (Aziz et al. 2008). The cutoff FDR-adjusted $P$ value used was 0.01 , with a minimum twofold change.

\section{SQ RT-PCR and analysis.}

RT was performed in a $20-\mu$ reaction mixture containing $2.5 \mu \mathrm{g}$ of total RNA, random primers at $200 \mathrm{ng} / \mu \mathrm{g}$ of RNA (Promega Corp.), and $30 \mathrm{U}$ of Avian myeloblastosis virus reverse transcriptase, following the manufacturer's instructions. Conditions used for RT were $65^{\circ} \mathrm{C}$ for $3 \mathrm{~min}, 25^{\circ} \mathrm{C}$ for $10 \mathrm{~min}, 42^{\circ} \mathrm{C}$ for $90 \mathrm{~min}$, and $70^{\circ} \mathrm{C}$ for $10 \mathrm{~min}$. The primers 16s_M130_Rv/Fw were used to measure the transcription of $16 \mathrm{~S}$ rRNA. Second-strand synthesis was performed using GoTaq Flexi polymerase (Promega Corp.) with $1 \mu \mathrm{l}$ of undiluted (any test gene) or 1:1,000 diluted (16S rRNA) cDNA reaction as template. The number of PCR cycles for each gene was standardized so that the product amplification was in the linear range; 10 to $20 \mu \mathrm{l}$ of the PCR product was analyzed by agarose gel electrophoresis. The intensities of the bands were measured and normalized to that of 16S rRNA using Kodak 1D software (Pizzonia 2001) to obtain the fold difference. The validation of each gene was performed with samples from three independent isolations.

\section{Plant endophytic colonization assays.}

'Baldo' rice seed were surface sterilized through a 1-h wash with $2.5 \%$ sodium hypochlorite, followed by several washes with sterile water. Seed were then aseptically transferred to sterile boxes with a thin layer of sterile water for seed pregermination. Following incubation for 5 days at $28^{\circ} \mathrm{C}$ in the absence of light, the pregerminated rice seed were aseptically transferred to 50-ml Falcon tubes containing $35 \mathrm{ml}$ of a modified Jensen's N-free plant nutrient medium (Somasegaran and Hoben 1994) with $0.3 \%$ agar.
Plant infection and endophytic bacteria isolation was conducted as previously described (Mattos et al. 2008). Briefly, plantlet infection assays were carried out by inoculation of $2 \times$ $10^{7} \mathrm{CFU}$ into each Falcon tube containing rice plantlets. After incubation for 14 days with a 12 -h photoperiod at $28^{\circ} \mathrm{C}$, plantlets were collected and cut, in order to gather only the roots. The excised plant segments were subjected to surface sterilization with $1 \%$ sodium hypochlorite for $5 \mathrm{~min}$, followed by several washes with sterile water. The roots were then weighed, transferred to sterile mortars containing $1 \mathrm{ml}$ of sterile phosphate-buffered saline (PBS), and macerated with a pestle. From each suspension, a series of 10 -fold dilutions were prepared using sterile PBS, and aliquots of $100 \mu \mathrm{l}$ were spread plated onto KB medium containing Rif for the isolation of $B$. kururiensis M130 WT, or Rif and Km for the isolation of $B$. kururiensis M130 derivatives. Plates were incubated for 2 days at $28^{\circ} \mathrm{C}$. Bacterial quantification was expressed as $\mathrm{CFU}$ per gram of fresh weight plant tissue and eight replicates from two independent colonizing assays were used to determine the average CFU values.

\section{$\beta$-Glucuronidase assays and histochemical staining for $\beta$-glucuronidase activity.}

$\beta$-Glucuronidase activities were determined as described previously (Ferluga and Venturi 2009) with B. kururiensis mutants grown in the presence or absence of rice plant extract. All experiments were performed in triplicate, and the mean value is given.

For histochemical staining, at least three seedlings from two independent inoculations were collected 12 days after inoculation and their roots stained for $\beta$-glucuronidase activity in 50 $\mathrm{mM}$ potassium phosphate buffer $(\mathrm{pH} 7.0)$ containing X-GlcU at $500 \mu \mathrm{g} \mathrm{ml}^{-1}$ overnight at $37^{\circ} \mathrm{C}$ in darkness. The reaction was subsequently cleared in $70 \%$ ethanol before visualization. $\beta$ Glucuronidase expression was examined with an stereomicroscope (MZ125; Leica) and images were recorded with a digital microscope camera (DFC420c; Leica).

\section{Swimming motility assay.}

For bacterial motility assays, B. kururiensis M130 was grown in $\mathrm{KB}$ media for $24 \mathrm{~h}$ at $30^{\circ} \mathrm{C}$ and adjusted to an optical density of 1.0. Adjusted culture $(1 \mu \mathrm{l})$ was spotted onto the center and inside of $0.3 \% \mathrm{~KB}$ agar plates containing or not containing $5 \%$ macerated rice plant. The plates were incubated at room temperature, the diameter of swimming was measured in three dimensions after $48 \mathrm{~h}$, and the mean values were calculated. All the experiments were performed in triplicate and the mean values and standard deviations are presented in the text.

\section{ACKNOWLEDGMENTS}

B. G. Coutinho's Ph.D. program is funded by CAPES (Brazil). Part of this work was also financially supported by ICGEB and by AGER Progetto RISINNOVA grant number 2010-2369. We thank S. Subramoni, G. Devescovi, I. Bertani, D. Passos da Silva, H. Patel, and Z. R. SuarezMoreno for reading the manuscript and for their support and interest in this work.

\section{LITERATURE CITED}

Andre, G., Even, S., Putzer, H., Burguiere, P., Croux, C., Danchin, A., Martin-Verstraete, I., and Soutourina, O. 2008. S-box and T-box riboswitches and antisense RNA control a sulfur metabolic operon of Clostridium acetobutylicum. Nucleic Acids Res. 36:5955-5969.

Aziz, R., Bartels, D., Best, A., DeJongh, M., Disz, T., Edwards, R., Formsma, K., Gerdes, S., Glass, E., Kubal, M., Meyer, F., Olsen, G., Olson, R., Osterman, A., Overbeek, R., McNeil, L., Paarmann, D., Paczian, T., Parrello, B., Pusch, G., Reich, C., Stevens, R., Vassieva, O., 
Vonstein, V., Wilke, A., and Zagnitko, O. 2008. The RAST server: rapid annotations using subsystems technology. BMC Genomics 9:75.

Baldani, J. I., Caruso, L., Baldani, V. L. D., Goi, S. R., and Dobereiner, J. 1997a. Recent advances in BNF with non-legume plants. Soil Biol. Biochem. 29:911-922.

Baldani, V. L., Oliveira, E., Balota, E., Baldani, J. I., Kirchhof, G., and Döbereiner, J. 1997b. Burkholderia brasilensis sp. nov. uma nova espécie de bactéria diazotrófica endofítica. An. Acad. Bras. Cienc. 69:1.

Baldani, V. L., Baldani, J. I., and Döbereiner, J. 2000. Inoculation of rice plants with the endophytic diazotrophs Herbaspirillum seropedicae and Burkholderia spp. Biol. Fertil. Soils 30:485-491.

Basler, M., Pilhofer, M., Henderson, G. P., Jensen, G. J., and Mekalanos, J. J. 2012. Type VI secretion requires a dynamic contractile phage tail-like structure. Nature 483:182-186.

Basler, M., Ho, B. T., and Mekalanos, J. J. 2013. Tit-for-tat: Type VI secretion system counterattack during bacterial cell-cell interactions. Cell 152:884-894.

Better, M., Lewis, B., Corbin, D., Ditta, G., and Helinski, D. R. 1983. Structural relationships among Rhizobium meliloti symbiotic promoters. Cell 35:479-485.

Bingle, L. E., Bailey, C. M., and Pallen, M. J. 2008. Type VI secretion: A beginner's guide. Curr. Opin. Microbiol. 11:3-8.

Bladergroen, M. R., Badelt, K., and Spaink, H. P. 2003. Infection-blocking genes of a symbiotic Rhizobium leguminosarum strain that are involved in temperature-dependent protein secretion. Mol. Plant-Microbe Interact. $16: 53-64$

Bohm, M., Hurek, T., and Reinhold-Hurek, B. 2007. Twitching motility is essential for endophytic rice colonization by the $\mathrm{N}_{2}$-fixing endophyte Azoarcus sp. strain BH72. Mol. Plant-Microbe Interact. 20:526-533.

Briani, F., Curti, S., Rossi, F., Carzaniga, T., Mauri, P., and Deho, G. 2008. Polynucleotide phosphorylase hinders mRNA degradation upon ribosomal protein S1 overexpression in Escherichia coli. RNA 14:2417-2429.

Burse, A., Weingart, H., and Ullrich, M. S. 2004. The phytoalexin-inducible multidrug efflux pump AcrAB contributes to virulence in the fire blight pathogen, Erwinia amylovora. Mol. Plant-Microbe Interact. 17:43-54.

Cascales, E. 2008. The type VI secretion toolkit. EMBO (Eur. Mol. Biol. Organ.) Rep. 9:735-741.

Compant, S., Clement, C., and Sessitsch, A. 2010. Plant growth-promoting bacteria in the rhizo- and endosphere of plants: Their role, colonization, mechanisms involved and prospects for utilization. Soil Biol. Biochem. 42:669-678

Cordeiro, F. A., Tadra-Sfeir, M. Z., Huergo, L. F., de Oliveira Pedrosa, F., Monteiro, R. A., and de Souza, E. M. 2013. Proteomic analysis of Herbaspirillum seropedicae cultivated in the presence of sugar cane extract. J. Proteome Res. 12:1142-1150.

Coutinho, B. G., Mitter, B., Talbi, C., Sessitsch, A., Bedmar, E. J., Halliday, N., James, E. K., Cámara, M., and Venturi, V. 2013a. Regulon studies and in planta role of the $\mathrm{Bral} / \mathrm{R}$ quorum sensing system in the plant beneficial Burkholderia cluster. Appl. Environ. Microbiol. 79:44214432.

Coutinho, B. G., Passos da Silva, D., Previato, J. O., Mendonça-Previato, L., and Venturi, V. 2013b. Draft genome sequence of the rice endophyte Burkholderia kururiensis M130. Genome Announc. 1:e0225-00212.

Dörr, J., Hurek, T., and Reinhold-Hurek, B. 1998. Type IV pili are involved in plant-microbe and fungus-microbe interactions. Mol. Microbiol. 30:7-17.

dos Santos, M. F., Muniz de Padua, V. L., de Matos Nogueira, E., Hemerly, A. S., and Domont, G. B. 2010. Proteome of Gluconacetobacter diazotrophicus co-cultivated with sugarcane plantlets. J. Proteomics 73:917931.

Draper, D. E., Pratt, C. W., and von Hippel, P. H. 1977. Escherichia coli ribosomal protein S1 has two polynucleotide binding sites. Proc. Natl. Acad. Sci. U.S.A. 74:4786-4790.

Felix, G., Duran, J. D., Volko, S., and Boller, T. 1999. Plants have a sensitive perception system for the most conserved domain of bacterial flagellin. Plant J. 18:265-276.

Ferluga, S., and Venturi, V. 2009. OryR is a LuxR-family protein involved in interkingdom signaling between pathogenic Xanthomonas oryzae pv. oryzae and rice. J. Bacteriol. 191:890-897.

Ferluga, S., Bigirimana, J., Hofte, M., and Venturi, V. 2007. A LuxR homologue of Xanthomonas oryzae pv. oryzae is required for optimal rice virulence. Mol. Plant. Pathol. 8:529-538.

Filiatrault, M. J., Stodghill, P. V., Bronstein, P. A., Moll, S., Lindeberg, M., Grills, G., Schweitzer, P., Wang, W., Schroth, G. P., Luo, S., Khrebtukova, I., Yang, Y., Thannhauser, T., Butcher, B. G., Cartinhour, S., and Schneider, D. J. 2010. Transcriptome analysis of Pseudomonas syringae identifies new genes, noncoding RNAs, and antisense activity. J. Bacteriol. 192:2359-2372.

Filloux, A., Hachani, A., and Bleves, S. 2008. The bacterial type VI secre- tion machine: Yet another player for protein transport across membranes. Microbiology 154:1570-1583.

Fischer, H. M. 1994. Genetic regulation of nitrogen fixation in rhizobia. Microbiol. Rev. 58:352-386.

Georg, J., and Hess, W. R. 2011. cis-Antisense RNA, another level of gene regulation in bacteria. Microbiol. Mol. Biol. Rev. 75:286-300.

Hardoim, P. R., Overbeek, L., and Van Elsas, J. D. 2008. Properties of bacterial endophytes and their proposed role in plant growth. Trends Microbiol. 16:463-471.

King, E. O., Ward, M. K., and Raney, D. E. 1954. Two simple media for the demonstration of pyocyanin and fluorescin. J. Lab. Clin. Med. 44:301-307.

Körner, H., Sofia, H. J., and Zumft, W. G. 2003. Phylogeny of the bacterial superfamily of Crp-Fnr transcription regulators: Exploiting the metabolic spectrum by controlling alternative gene programs. FEMS (Fed. Eur. Microbiol. Soc.) Microbiol. Rev. 27:559-592.

Kunze, G., Zipfel, C., Robatzek, S., Niehaus, K., Boller, T., and Felix, G. 2004. The $\mathrm{N}$ terminus of bacterial elongation factor Tu elicits innate immunity in Arabidopsis plants. Plant Cell 16:3496-3507.

Ladha, J. K., and Reddy, P. M. 1995. Extension of nitrogen fixation to rice-Necessity and possibilities. GeoJournal 35:363-372.

Ladha, J. K., de Bruijn, F. J., and Malik, K. A. 1997. Introduction: Assessing opportunities for nitrogen fixation in rice-A frontier project. Plant Soil 194:1-10.

Leiman, P. G., Basler, M., Ramagopal, U. A., Bonanno, J. B., Sauder, J. M., Pukatzki, S., Burley, S. K., Almo, S. C., and Mekalanos, J. J. 2009. Type VI secretion apparatus and phage tail-associated protein complexes share a common evolutionary origin. Proc. Natl. Acad. Sci. U.S.A. 106:4154-4159

Lery, L. M., von Kruger, W. M., Viana, F. C., Teixeira, K. R., and Bisch, P. M. 2008. A comparative proteomic analysis of Gluconacetobacter diazotrophicus PAL5 at exponential and stationary phases of cultures in the presence of high and low levels of inorganic nitrogen compound. Biochim. Biophys. Acta 1784:1578-1589.

Lluch-Senar, M., Vallmitjana, M., Querol, E., and Pinol, J. 2007. A new promoterless reporter vector reveals antisense transcription in $\mathrm{Myco}$ plasma genitalium. Microbiology 153:2743-2752.

Mark, G. L., Dow, J. M., Kiely, P. D., Higgins, H., Haynes, J., Baysse, C., Abbas, A., Foley, T., Franks, A., Morrissey, J., and O'Gara, F. 2005 Transcriptome profiling of bacterial responses to root exudates identifies genes involved in microbe-plant interactions. Proc. Natl. Acad. Sci. U.S.A. 102:17454-17459.

Mattinen, L., Somervuo, P., Nykyri, J., Nissinen, R., Kouvonen, P., Corthals, G., Auvinen, P., Aittamaa, M., Valkonen, J. P., and Pirhonen, M. 2008 Microarray profiling of host-extract-induced genes and characterization of the type VI secretion cluster in the potato pathogen Pectobacterium atrosepticum. Microbiology 154:2387-2396.

Mattos, K. A., Padua, V. L., Romeiro, A., Hallack, L. F., Neves, B. C. Ulisses, T. M., Barros, C. F., Todeschini, A. R., Previato, J. O., and Mendonca-Previato, L. 2008. Endophytic colonization of rice (Oryza sativa L.) by the diazotrophic bacterium Burkholderia kururiensis and its ability to enhance plant growth. An. Acad. Bras. Cienc. 80:477-493.

Mortazavi, A., Williams, B. A., McCue, K., Schaeffer, L., and Wold, B. 2008. Mapping and quantifying mammalian transcriptomes by RNASeq. Nat. Methods 5:621-628.

O'Toole, G., and Kolter, R. 1998a. Initiation of biofilm formation in Pseudomonas fluorescens WCS365 proceeds via multiple, convergent signalling pathways: A genetic analysis. Mol. Microbiol. 28:449-461

O'Toole, G. A., and Kolter, R. 1998b. Flagellar and twitching motility are necessary for Pseudomonas aeruginosa biofilm development. Mol. Microbiol. 30:295-304

Pizzonia, J. 2001. Electrophoresis gel image processing and analysis using the KODAK 1D software. Biotechniques 30:1316-1320.

Rediers, H., Bonnecarrere, V., Rainey, P. B., Hamonts, K., Vanderleyden, J., and De Mot, R. 2003. Development and application of a $\operatorname{dapB}$-based in vivo expression technology system to study colonization of rice by the endophytic nitrogen-fixing bacterium Pseudomonas stutzeri A15. Appl. Environ. Microbiol. 69:6864-6874.

Reeve, W. G., Tiwari, R. P., Worsley, P. S., Dilworth, M. J., Glenn, A. R., and Howieson, J. G. 1999. Constructs for insertional mutagenesis, transcriptional signal localization and gene regulation studies in root nodule and other bacteria. Microbiology 145:1307-1316.

Reinhold-Hurek, B., and Hurek, T. 1998. Life in grasses: Diazotrophic endophytes. Trends Microbiol. 6:139-144.

Reinhold-Hurek, B., and Hurek, T. 2011. Living inside plants: Bacterial endophytes. Curr. Opin. Plant Biol. 14:435-443.

Sambrook, I., Fritsch, F., and Maniatis, T. 1989. Molecular Cloning: A Laboratory Manual. Cold Spring Harbor Laboratory Press, Cold Spring Harbor, NY, U.S.A.

Schmidtke, C., Findeiss, S., Sharma, C. M., Kuhfuss, J., Hoffmann, S. 
Vogel, J., Stadler, P. F., and Bonas, U. 2012. Genome-wide transcriptome analysis of the plant pathogen Xanthomonas identifies sRNAs with putative virulence functions. Nucleic Acids Res. 40:2020-2031.

Shidore, T., Dinse, T., Öhrlein, J., Becker, A., and Reinhold-Hurek, B. 2012. Transcriptomic analysis of responses to exudates reveal genes required for rhizosphere competence of the endophyte Azoarcus sp. strain BH72. Environ. Microbiol. 14:2775-2787.

Simon, R., Priefer, U., and Puhler, A. 1983. A broad host range mobilization system for in vivo genetic engineering: Transposon mutagenesis in Gram-negative bacteria. Nat. Biotechnol. 1:784-791.

Somasegaran, P., and Hoben, H. J. 1994. Handbook for Rhizobia: Methods in Legume-Rhizobium Technology. Springer-Verlag, New York.

Sorensen, M. A., Fricke, J., and Pedersen, S. 1998. Ribosomal protein S1 is required for translation of most, if not all, natural mRNAs in Escherichia coli in vivo. J. Mol. Biol. 280:561-569.

Suárez-Moreno, Z. R., Caballero-Mellado, J., and Venturi, V. 2008. The new group of non-pathogenic plant-associated nitrogen-fixing Burkholderia spp. shares a conserved quorum-sensing system, which is tightly regulated by the RsaL repressor. Microbiology 154:2048-2059.

Suárez-Moreno, Z. R., Devescovi, G., Myers, M., Hallack, L., MendonçaPreviato, L., Caballero-Mellado, J., and Venturi, V. 2010. Commonalities and differences in $\mathrm{N}$-acyl homoserine lactone quorum sensing regulation in the species cluster of beneficial plant associated Burkholderia. Appl. Environ. Microbiol. 76:4302-4317.

Subramanian, A. R. 1983. Structure and functions of ribosomal protein S1. Prog. Nucleic Acid Res. Mol. Biol. 28:101-142.

Subramoni, S., Gonzalez, J. F., Johnson, A., Pechy-Tarr, M., Rochat, L. Paulsen, I., Loper, J. E., Keel, C., and Venturi, V. 2011. Bacterial subfamily of LuxR regulators that respond to plant compounds. Appl. Environ. Microbiol. 77:4579-4588.

Thomason, M. K., and Storz, G. 2010. Bacterial antisense RNAs: How many are there, and what are they doing? Annu. Rev. Genet. 44:167-188. 